\title{
Viajes al futuro y sociedad del simulacro: Modernidad, Dis- neyficación y ruinas de la resistencia en Quinteto de Buenos Aires de Manuel Vázquez Montalbán
}

\section{WILLIAM NICHOLS}

A lo largo de la obra de Manuel Vázquez Montalbán, tanto en las obras dentro de la serie Carvalho como fuera y en la producción de libros noficción, el viaje sirve como ímpetu narrativo además de eje temático para indagar las contradicciones de la globalización y explorar la memoria como estrategia de resistencia. Por un lado, el viaje ofrece una metáfora que evoca la supuesta disolución de las fronteras dentro del contexto globalizado y el libre movimiento de personas, productos y capital. Por otro, la mirada crítica del viajero cuestiona la autenticidad de la sociedad globalizada que esconde los escombros del pasado bajo las superficies lisas y brillantes de las ciudades rediseñadas bajo la lógica Disney del simulacro. El viaje está presente en la producción literaria de Vázquez Montalbán desde la primera aparición de Carvalho en Yo maté a Kennedy (1972) hasta los últimos tomos de Milenio I y II (2004). El propósito de este ensayo es analizar el tema del viaje en Quinteto de Buenos Aires (1997) como un vehículo que pone en marcha una investigación que cuestiona la capacidad de resistir la globalización, encontrar la autenticidad cultural, y preservar la memoria y el pensamiento crítico. En este ensayo, el autor considerará a Vázquez Montalbán como una voz profética que anunciaba los efectos demoledores para el pensamiento crítico con la creación del "Gran consumidor" que él describía en Panfleto desde el planeta de los simios (1995).

El viaje, igual que la investigación del detective, le ofrece a Vázquez Montalbán una especie de mecanismo hermenéutico por medio del cual el personaje (o el autor mismo en el caso de las obras de no-ficción) visita las "escenas del crimen" y explora las contradicciones de un mundo globalizado y sus víctimas. En las novelas de Vázquez Montalbán, tanto las de la serie Carvalho como aquellas fuera de la serie, la investigación del detective se desdobla y se vuelve una investigación en múltiples niveles donde la resolución del crimen resulta ser un pretexto para entablar otras indagaciones sobre la desigualdad política y económica, la memoria histórica y el pasado de represión, las promesas y los fracasos del proyecto de la modernidad, y más. Si la investigación presenta una es- 
tructura epistemológica para entablar una exploración de la sociedad globalizada, el viaje es el mecanismo para desplazar la investigación de una forma que presenta una radiografía tridimensional del mundo al trazar las diferencias sociales e ideológicas, grabar el mosaico de discursos individuales y colectivos, retratar distintos modelos de desarrollo urbano, y cuestionar la autenticidad cultural. Por la mirada, Carvalho y el mismo Vázquez Montalbán (y por extensión el lector), se vuelven testigos en sus viajes y dejan de ser "ojos privados" (otro nombre para un detective en inglés) al descubrir para los "ojos públicos" el desorden detrás de la fachada de orden proyectado por la globalización y articulado por el discurso neoliberal.

Dean MacCannell escribe en su clásico libro The Tourist: A New Theory of the Leisure Class (1976) que la modernidad y los procesos de modernización no se presentan con un propósito claro y una finalidad entendible para todos sino que se perciben como un proyecto compuesto de fragmentos desorganizados, derrochadores, violentos, superficiales, inestables, no planificados, e inauténticos. MacCannell reconoce, sin embargo, que mientras la experiencia individual y colectiva en la sociedad puede dar una sensación desigual, desorganizada, y desconcertante, por debajo de este exterior desordenado hay una intención firme de establecer los "valores modernos" a nivel global (2). Se podría decir que lo que MacCannell describe son los inicios de un pensamiento neoliberal que empieza a expandirse a nivel mundial en lo que más tarde se denominaría "globalización" e implicaría no sólo los procesos económicos de la modernización sino los efectos culturales también, especialmente en el ámbito de la comunicación de masas y la creación de una cultura postmoderna del simulacro. La sensación de inestabilidad e inautenticidad en la sociedad moderna es, irónicamente, lo que impulsan los procesos de modernización como un intento de aliviar el sentimiento de desorden, pero también es esta sensación lo que crea una "unifying consciousness" [conciencia unificadora] (2) en la sociedad moderna que piensa que lo real y lo auténtico reside en otro lugar, en otros momentos históricos, en otras culturas, en otros estilos de vida más simples y más puros. Desde la perspectiva occidental, este lugar "puro" suele ser el "sur", los lugares como Asia, América Latina y África que se perciben como no tocados por la modernidad. La tesis central de MacCannell es que la expansión empírica e ideológica de la sociedad moderna está conectada íntimamente y en diversas maneras con el desarrollo del turismo internacional y el fenómeno de "sightseeing" (que en español sólo se entiende como "hacer 
turismo") como elemento fundamental del ocio masivo en el mundo moderno.

Lo que MacCannell ha descubierto es que el acto de viajar y "hacer turismo" se debe considerar como un rito, típicamente de la clase media, que se hace como forma de contestar las diferenciaciones de la sociedad. ${ }^{1}$ Es decir, hacer turismo es un intento a nivel colectivo tanto como individual de buscar trascendencia y sobrepasar la discontinuidad de la experiencia moderna por medio de una experiencia unificadora y totalizadora. Las diferenciaciones del mundo -sean culturales, económicas, geográficas, étnicas, históricas, etc.- se desplazan de su contexto social, natural y original para ser reconstituidas y reintegradas en una narrativa que afirma su autenticidad en la reconstrucción de una identidad social y un patrimonio cultural (13). Desde la perspectiva de John Urry en The Tourist Gaze la reconstitución y la reintegración del orden se afirma al imponer una narrativa clara y entendible por medio de la mirada del turista que observa y consume, visual además de económicamente, los objetos y las atracciones turísticas. Urry concuerda con MacCannell en que la experiencia turística es, en su esencia, una búsqueda de lo real y lo auténtico en otros lugares y en otros tiempos alejados de la vida cotidiana del viajero. Pero para Urry, la creación de lo que MacCannell llama "pseudo-eventos" o una "autenticidad escenificada" representa un intento de dirigir y construir la mirada del viajero con signos, o sea los objetos y las atracciones turísticas, que a su vez el turista colecciona con la mirada para afirmar la narrativa que se había construido originalmente para su mirada. ${ }^{2}$ Es más, la misma mirada se legitima al objetivarse material-

$-$

${ }^{1}$ La idea de diferenciación que propone MacCannell aquí viene del trabajo de Claude Lévi-Strauss y la disciplina de antropología estructural donde se examinan las diferencias entre clases sociales, estilos de vida, grupos étnicos y raciales, géneros, rangos de edad, grupos profesionales y políticos, y la representación mítica del pasado. La diferenciación es una variable sistémica, dice MacCannell, en el sentido que no se reduce a una institución específica de la sociedad ni se origina en una institución o lugar para expandirse a otros. Es algo que opera independiente y simultáneamente por toda la sociedad. La diferenciación es a la vez el origen de alternativas que da la sensación de libertad en la sociedad moderna pero también es lo que provoca la percepción de contradicciones, conflictos, violencia, fragmentación, y alienación como las características que más tipifican la existencia moderna.

${ }^{2}$ Urry nota y clasifica seis tipos distintos, pero interrelacionados, de miradas: la mirada de un objeto único, la mirada de un signo particular, la mirada de aspectos no familiares de algo que previamente se había considerado familiar, la mi- 
mente con fotografías, tarjetas postales, películas, o recuerdos, los cuales permiten que esta mirada (y el consumo de los signos) se reproduzcan al infinito como una especie de mise en abyme. ${ }^{3}$ La mirada del viajero, entonces, no sólo consume los objetos, los lugares, las atracciones y las experiencias sino que su "reproducción mecánica", como diría Walter Benjamin, ofrece un simulacro de lo real y lo auténtico que busca el turista que, irónicamente, afirma la narrativa de la autenticidad que buscaba. En esta reproducción de la mirada, además, se recalcan los valores del consumo que constituyen y que informan la propia mirada turística. Es de esta forma que Urry afirma la validez del estudio del turismo como un campo de investigación legítimo porque es por los objetos de la mirada turística que se puede interrogar los procesos y los sistemas de la sociedad, además de su propia organización y estructura, que nos parecen normales e invisibles. Lejos de ser un campo trivial, afirma Urry, el turismo es significante en su habilidad de revelar los aspectos de las prácticas normales que de otra forma hubieran quedado "opacos" (2).

Este deseo de interrogar lo opaco y de perforar la llamada "ilusión de transparencia" es precisamente la razón por la cual Vázquez Montalbán adopta y adapta las estructuras de la novela policíaca norteamericana para expresar sus frustraciones con la (post)modernidad y ofrecer una radiografía de la sociedad. Por un lado, la estructura hermenéutica de la novela policíaca le permite a Vázquez Montalbán entablar una serie de investigaciones concéntricas y entrelazadas que empieza con el deseo de solucionar algún crimen, normalmente un asesinato, pero que luego pueden conducir a diversas exploraciones: en torno a la memoria histórica, el cuestionamiento de la identidad en la sociedad de comunicación de masas, la posibilidad de la justicia social en la era de la globalización, la contemplación de los valores políticos (tanto de la izquierda como de la derecha) en un ambiente de corrupción y conveniencia política, y la ins-

rada de aspectos cotidianos de la vida social que las personas hacen en contextos inusuales, la mirada de actividades familiares en un contexto visual inusual, y la mirada de signos particulares que indican que algún otro objeto es extraordinario aunque no lo parezca (12-13).

${ }^{3}$ La imagen visual que se usa a menudo para explicar el concepto del mise en abyme es la de dos espejos, uno frente al otro, que producen una infinita reproducción de reflejos. En los dos textos que analizo aquí, la metáfora del espejo está muy presente. En otros contextos, Manuel Vázquez Montalbán ha recurrido al concepto del "ourobouros" que es la imagen de una serpiente comiendo su propia cola. Esta imagen también comunica la idea de una reproducción infinita además de la auto-destrucción al consumirse a uno mismo. 
pección de las estructuras, los códigos, las convenciones y los propósitos de la misma literatura. El género negro, además, es un modelo que Vázquez Montalbán adopta de escritores norteamericanos como Dashiell Hammett, Raymond Chandler, Jim Thompson y otros que producían una literatura popular en una época de "capitalismo salvaje" que pretendía des-cubrir la presencia endémica del crimen y la corrupción en el ambiente urbano donde el llamado sueño americano se había convertido en pesadilla que victimiza a sus ciudadanos y muestra una culpabilidad colectiva en la sociedad. La misma estructura investigativa que aporta a la serie Carvalho la capacidad de esbozar y describir las transformaciones políticas de España también le permite deconstruir la "construcción" de la realidad. Carvalho no sólo descifra lo misterioso y desenmascara la inmoralidad y la hipocresía de la sociedad sino que también descodifica los mecanismos de enmascaramiento cultural desde su estatus privilegiado como un "mirón" auto-consciente. Vázquez Montalbán se refiere a Carvalho, irónicamente, como un disfraz que esconde al novelista a la vez que le presenta un instrumento por el cual pudo contemplar los aparatos culturales que enmarcan y fabrican la realidad mientras se tapa la misma inspección voyerista con la fachada de ficción (Nichols 1998, 207). La presencia de Carvalho, entonces, le ofrece a Vázquez Montalbán una coartada para comentar tanto los procesos sociales, políticos y económicos como también los literarios, discursivos, ideológicos y culturales con una voz que se distancia de la suya. Como Sam Spade en $E l$ halcón maltés, Carvalho le permite al lector quitar la tapadera y "look at the works" [mirar adentro] (66) de la realidad y descubrir el mosaico de influencias que condicionan la conciencia individual y colectiva.

Para Vázquez Montalbán, el hecho de importar un modelo literario norteamericano ofrece un paralelo irónico a la importación del modelo económico neoliberal (norteamericano) durante la época de la Transición en España. Por medio de un género nacido en una crisis económica y política Vázquez Montalbán aprovecha la mirada del detective privado que viaja por la sociedad, pasando las fronteras geográficas además de las barreras entre las clases sociales, para destacar las promesas y fracasos de la (post)modernidad en España, reconocer los perdedores y los ganadores de la Transición (que muchas veces se asemejan a los de la Guerra Civil española), y buscar la revitalización de un proyecto político de izquierdas que afirme el papel social del intelectual en la época de la globalización. Si para MacCannell y Urry el deseo de buscar lo real y encontrar lo auténtico en el mundo son los motivos del viaje del turista, muchos personajes en los escritos de Vázquez Montalbán (dentro y fuera 
del ciclo Carvalho) emprenden un viaje por motivos similares que salen de una frustración con la modernidad y con el proyecto de modernización en España (y el mundo occidental), además del desencanto con la ideología estancada de la izquierda durante la Transición. Cómo he mencionado arriba, el tema del viaje es recurrente en los textos de Vázquez Montalbán y muy a menudo los personajes, incluso el propio Carvalho, intentan escapar de su frustración con una España postmoderna al huir de su situación geográfica o de su ubicación en términos de clase social en busca de una utopía elusiva. Se nota el tema del viaje en Tatuaje (1974), Asesinato en el Comité Central (1981) y Los pájaros de Bangkok (1983) además de Quinteto en Buenos Aires (1997) y El balneario (1986) donde Carvalho viaja a Ámsterdam, Madrid, Tailandia, y Argentina, respectivamente, y en el último busca refugio en un remoto y exclusivo centro de salud. La desilusión personal en algunos de los personajes de Los mares del sur (1979), La rosa de Alejandría (1984), El delantero centro fue asesinado al atardecer (1989), Los pájaros de Bangkok y El hombre de mi vida (2000) ofrece un reflejo especular del sentimiento de "desencanto" en España y la sensación de desilusión con la modernidad. El viaje, entonces, ofrece para estos personajes un escape del desorden social, político y económico que caracteriza los primeros años de la Transición. En Milenio I y II (2004), publicados póstumamente, Carvalho huye de Barcelona después de matar a Anfrúns, un personaje que aparece en varias de las entregas en el ciclo Carvalho y representa una especie de anti-Carvalho en la figura de un "progre" que abandona su ideología izquierdista y su pasado contracultural para aprovechar las oportunidades, sexuales y financieras, de la nueva sociedad abierta, democrática y moderna en España. Carvalho se vuelve un "náufrago," un autodenominado Robinsón Crusoe, aislado en un mundo globalizado donde viaja con su asistente, Biscuter, por ruinas postcoloniales que se han transformado en atracciones exóticas que sirven los intereses capitalistas del turismo global (Nichols 17). En vez de encontrar lo real y la autenticidad para contrarrestar el desorden del que escapaba, Carvalho y Biscuter descubren un mundo donde la autenticidad cultural se ha usurpado para los intereses de capitalismo multinacional y los antiguos modos económicos de hegemonía se perpetúan bajo el maquillaje de la globalización donde la sociedad se divide entre "globalizadores y globalizados" (Milenio I, 266).

El tema del viaje se presenta también en algunas novelas de Vázquez Montalbán fuera de la serie Carvalho como Galíndez (1991), donde la tortura y el asesinato de un representante político del Gobierno del País 
Vasco en el exilio en los años 50 implica a la CIA y la dictadura de Trujillo en la República Dominicana, y obras de no-ficción como Y Dios entró en la Habana (1998), en la cual Vázquez Montalbán explora las implicaciones históricas, políticas y económicas de la llegada del Papa Juan Pablo II a Cuba y su encuentro con Fidel Castro. Vázquez Montalbán también emprende un viaje él mismo para conversar con el subcomandante Marcos en Marcos: El señor de los espejos (1999), donde exploran la posibilidad de resistencia y revolución y la necesidad de revitalizar el proyecto social de izquierdas en una cultura de simulacros y la inundación de medios de comunicación de masas. A lo largo de la obra de Vázquez Montalbán se presenta una frustración con la cultura del simulacro y las tácticas enmascaradoras de lo que Marcos llama la "teología neoliberal" (13) que ofuscan los mecanismos de poder bajo la superficie lisa y brillante de las imágenes transmitidas por los medios de comunicación de masas. El autor se posiciona críticamente frente a la "Disneyficación" de la sociedad (que se manifiesta físicamente en las transformaciones urbanas), donde la llamada "ilusión de transparencia" (de acuerdo a Lefebvre) construye un espejismo de orden que esconde la violencia y el desorden del sistema capitalista. Por un lado, el motivo del viaje le permite a Vázquez Montalbán investigar la capacidad (o falta de ella) de ejercer la voluntad y la agencia individual contra la inculcación cultural. Por otro lado, el viaje también sirve para examinar la posibilidad de revitalizar el discurso estancado de la izquierda al redefinir su proyecto social para ofrecer estrategias de resistencia en una cultura de consumo. Por el viaje Carvalho (y por extensión Vázquez Montalbán) busca una oportunidad de escapar de la confusión y la frustración que siente en España, tanto con el rediseño y el aburguesamiento (gentrificación) del espacio urbano en la Barcelona post-olímpica como con el estancamiento y vacuidad del pensamiento izquierdista. En La literatura en la construcción de la ciudad democrática, Vázquez Montalbán comenta la ironía de una ciudad que aparenta ser abierta pero donde las conductas libres están predeterminadas y el sujeto histórico democrático se ha deshistorificado en una sociedad que ha pasado del control del Gran Hermano al del Gran Consumidor. Las ciudades como Barcelona en las Olimpiadas y Sevilla durante la Expo (igual que muchos otros lugares en el mundo) ya no se pueden considerar como ejemplos de la ciudad democrática porque se han convertido en escenarios para teatralizar la postmodernidad e inutilizar el pensamiento crítico como "ciudad mercado, ciudad espectáculo, ciudad simulacro" (94). En Variations on a Theme Park: The New American City and the End of Public Space, Mi- 
chael Sorkin denomina este proceso de transformación "Disneyfication": las redes de comunicación y consumo sustituyen el cemento para construir un nuevo tipo de ciudad a-geográfica que no conecta con un lugar sino que borra lo físico para habitar lo conceptual, donde lo que falta no son los edificios o los lugares sino los espacios de transición que conectan los lugares para darles sentido (xi-xii). Para Sorkin, las calles y los centros que daban características legibles a las ciudades han cedido a las relaciones económicas que se conectan por las redes invisibles de comunicación para amenazar con "unimagined sameness" [una similitud inimaginada] (xiii), a la vez que se multiplican las opciones ilusorias de la televisión (sin contar hoy en día con el Internet y las redes sociales, los flujos transnacionales de cultura visual, los mensajes instantáneos, etc.). ${ }^{4}$

Esta sociedad del espectáculo y el simulacro condiciona al individuo según las demandas del mercado y conduce a lo que Harvey llama una "urbanization of consciousness" [urbanización de la conciencia] (249), donde los procesos de consumo y acumulación no sólo construyen los espacios urbanos sino que informan la experiencia cotidiana del individuo en esos espacios. Según Harvey, el individuo lee el orden simbólico del entorno urbano y lo internaliza de tal forma que los espacios, según sean prohibidos, temidos, ignorados, redundantes, cómodos o necesarios, definen quiénes somos, cómo nos entendemos, y cómo interactuamos con los demás (249-50). Al aprender el lenguaje de los espacios de la ciudad, se asimila y se normaliza la ideología y, además, las contradicciones del capitalismo, lo cual facilita la reproducción del estatus quo. El capitalismo, afirma Harvey, crea las condiciones que posibilitan el fetichismo de la ciudad al impulsar procesos de "creative destruction" [destrucción creativa] (250) donde los barrios proletarios y obreros se borran, y con ellos la memoria histórica de la ciudad y la sociedad, para dejar lugar (literalmente) al desarrollo urbano que apele a la mirada consumidora (especialmente la del turista). ${ }^{5}$ La confluencia (o con-fusión) del narcisismo del consumidor y el deseo de auto-realización fomenta una urbanización de la conciencia que intoxica al individuo con fetichismos. Estos no sólo enmascaran los mecanismos de poder con una retórica que defiende la agencia del sujeto por su capacidad de comprar y consumir sino que subvierte la posi-

\footnotetext{
${ }^{4}$ Véanse la obra de Manuel Castells y los escritos de Herbert Marcuse, en particular One Dimensional Man.

${ }^{5}$ Veáse Ways of Seeing de John Berger. También Baudrillard habla de cómo los espacios públicos se han convertido en espacios de publicidad.
} 
bilidad de movilización política para resistir los procesos del capitalismo. ${ }^{6}$ El propósito de Vázquez Montalbán a lo largo de su obra literaria es ofrecer una mirada crítica que revela el desorden por detrás del espejismo de orden en la ciudad mercado para destacar los ganadores y los perdedores del neoliberalismo a la vez que guarda la memoria de los pueblos y las personas olvidadas y borradas por la globalización. El autor percibe en el pasamontañas del subcomandante Marcos una adecuada metáfora para los efectos enmascaradores del sistema capitalista neoliberal y la sociedad del simulacro, donde los medios de comunicación inculcan la conciencia individual (y colectiva) con los valores de consumo. De esta forma, la pregunta que propone Vázquez Montalbán destaca una problemática central: ¿uno se mueve o es movido?

El viaje, entonces, se vuelve una estrategia para afirmar la agencia del individuo frente a la incertidumbre existencial dentro de una sociedad poblada de simulacros. En Quinteto de Buenos Aires (1997), Pepe Carvalho viaja a Buenos Aires en busca de su primo, quien fue uno de miles de desaparecidos durante la Junta Militar en los años 70. Por un lado, la búsqueda de su primo desaparecido evoca la represión política durante el Franquismo y la amnesia voluntaria en España durante la Transición y establece un vínculo entre la cuestión de la recuperación de la memoria histórica en España con la situación política en Argentina. La búsqueda de alguien desaparecido es un tema recurrente en muchas novelas negras y suele ser el ímpetu para que un cliente contrate al detective privado, pero en esta novela, el caso que acepta Carvalho le ofrece la posibilidad de buscar la justicia social contra el régimen de Franco y el ajuste de cuentas con la memoria histórica que le fue negada a la sociedad española en los años después de la muerte del dictador. Por otro lado, el viaje de Carvalho, de origen gallego, recuerda la larga historia de migraciones gallegas y los vínculos culturales entre España y Argentina, en especial las condiciones económicas y políticas que impulsaban la inmigración. Esta conexión transatlántica señala que había un movimiento global de personas, culturas e ideas antes de la época de la globalización y ofrece otra forma de contemplar la globalización desde la perspectiva humana, especialmente frente a las crisis migratorias de la actualidad. También se nota que el viaje de

${ }^{6}$ Estas preocupaciones por las influencias de los medios de comunicación de masas se presentan en la obra de Vázquez Montalbán desde el principio e informan sus "escritos subnormales" en los cuales explora la "subnormalización" de los seres humanos bajo los efectos delirantes de los medios de comunicación. Sobre este aspecto, véase Colmeiro 57-89. 
Carvalho a Argentina le ofrece una forma de escaparse de una ciudad que ya no reconoce. Más pasivo e introspectivo, Carvalho siente el impulso de abandonar una Barcelona que ha destruido sus memorias con las transformaciones urbanas, especialmente en el barrio chino que ha sido limpiado de sus "virus históricos" para convertirse en un "teatro profiláctico para interpretar la farsa de la modernidad" (16).

La transformación de Barcelona, especialmente el barrio del Raval, es un tema siempre presente en las novelas del ciclo Carvalho, en particular Los mares del sur (1979), considerada la novela urbana de la serie, y luego las entregas como El delantero centro fue asesinado al atardecer (1989) y El laberinto griego (1991) en las cuales las preparaciones para las Olimpiadas en Barcelona, en particular en el barrio de Poble Nou, entierran la ciudad histórica bajo una re-escritura, como una especie de palimpsesto urbano, según las demandas del capital. En las novelas del ciclo Carvalho después de las Olimpiadas -especialmente Sabotaje olímpico (1993), Quinteto de Buenos Aires (1997), El hombre de mi vida (2000) y Milenio Carvalho I y II (2004)- se nota el cansancio progresivo de Carvalho como se desilusiona con la transformación de Barcelona en un "no lugar" según el concepto de Augé, una especie de espacio "disneyficado" que premia el simulacro, el espectáculo y el consumo capitalista. Al principio de Quinteto de Buenos Aires, Carvalho contempla el espacio liminal entre la vieja y la nueva Barcelona Olímpica. Las transformaciones que empezaron en la Villa Olímpica frente al mar ahora se extienden hacia la "retaguardia" donde todo lo que no sirve para la nueva formación de la ciudad se manda al "desguace" (10-11). La ciudad se vuelve un campo de batalla donde no sólo se lucha por el terreno urbano sino también por la identidad, las memorias y las experiencias vividas allí como un espacio social que se pierde con la conversión de Barcelona en una utopía postmoderna y capitalista, fabricada según los impulsos consumistas. La voz narrativa emplea un vocabulario simbólico higienista y postindustrial para describir una Barcelona bajo ataque que se ha esterilizado: "la ciudad postolímpica, abierta al mar, surcada por vías rápidas, en plena destrucción el barrio Chino, las avionetas de lo políticamente correcto sobrevolando la ciudad, fumigándola para matar sus bacterias, sus virus históricos, las luchas sociales, el lumpen, ciudad sin ingles ya, ciudad de ingles extirpadas" (16). ${ }^{7}$

${ }^{7}$ Hay una sutil referencia a Tiempo de silencio (1962) de Luis Martín-Santos en el discurso biológico y la búsqueda de purificación científica. Martín-Santos explora los silencios de un discurso represivo que impone orden para establecer 
Barcelona, entonces, se ha vuelto una especie de utopía neoliberal al estilo Disney y la experiencia de Carvalho ejemplifica la paradoja que exploran Claudio Minca y Tim Oakes en Travels in Paradox: Remapping Tourism, donde examinan la tensión entre la percepción de una ciudad como parque temático y la experiencia cotidiana de los ciudadanos que viven y trabajan allí. Lo que destacan los autores es lo que llaman "a schizophrenic dualism of paradoxical modernity" (un dualismo esquizofrénico de una modernidad paradójica), según la cual el viajero busca la autenticidad y aplica una serie de valoraciones binarias que evalúan su experiencia como real o no real. Como resultado, declaran, los destinos se re-construyen como una versión auto-consciente de sí misma en la cual la realidad se proyecta como un espectáculo para satisfacer los signos de autenticidad que busca el viajero y para convencerle que el lugar que visita es auténtico. Tanto el viajero como el residente, entonces, asumen papeles distintos aunque relacionados, los primeros como consumidores y los otros como aportadores de significado, en la creación de un sentido de "lugar." Por medio de este intercambio y negociación de significado, tanto el viajero como el residente experimentan subjetividad y objetividad simultáneamente en la creación de un espacio ideológico cuyo diseño dirige el individuo al consumo con la apariencia de orden y lo que llaman los autores "ordered disorder" [el desorden ordenado] (11). Lo que sugieren Minca y Oates es que el turismo de viaje adquiere poder al construir un escenario en el cual actuamos una serie de oposiciones binarias que imponen orden en un mundo desordenado y dan sentido a un mundo caótico. A la vez, sin embargo, para poder establecer un escenario y realizar la objetificación de un lugar como destino se tiene que reconocer el carácter construido de las oposiciones binarias. El viaje, dicen Minca y Oates, resulta de un impulso de ordenar el mundo para poder entenderlo como un escape del desorden que nos confronta, de buscar un refugio y de intentar afirmar nuestra agencia por medio de nuestra movilidad (14).

una visión purificada de España durante la dictadura. En la novela, los elementos que provocan el desorden y la contaminación están expulsados del centro, se encuentran en las chabolas en el extrarradio de la sociedad. La contaminación se entiende a nivel metafórico como los elementos ideológicos, raciales, o sociales que no concuerdan con la visión franquista de una España "grande y libre". En el contexto neoliberal, el nuevo orden mundial también busca erradicar la contaminación de elementos inútiles que no sirven los fines y propósitos económicos del sistema. 
Lo que el turista experimenta, en Barcelona o cualquier otro destino, no es el lugar sino el orden - un mundo de falsificaciones, reproducciones, e imitaciones - que presenta una narrativa preparada para el consumo pasivo y no reflexivo, lo cual conduce a su formación como sujeto dentro del sistema neoliberal. Carvalho rechaza el orden de la ciudad simulacro en que se ha convertido Barcelona y afirma la responsabilidad que siente de arrancar la máscara para dejar ver la realidad: "La policía garantiza el orden. Yo me limito a descubrir el desorden" (Quinteto, 11). Para Carvalho, entonces, el viaje a Argentina le ofrece la oportunidad de abandonar una Barcelona antiséptica para descubrir la autenticidad de una ciudad como Buenos Aires que se auto-destruye: "Me gustan las ciudades que se autodestruyen. Las ciudades triunfales huelen a desodorante" (11). La construcción mental de la ciudad en la imaginación de Carvalho revela un entendimiento condicionado por los arquetipos (y estereotipos) más conocidos. Cuando le preguntan qué sabe de Argentina, el detective contesta, "Maradona, desaparecidos, tango" (20) y más tarde recurre a los mitos culturales más conocidos de Argentina: Evita, Gardel, Borges. Cuando le contestan, "Y mangantes, muchos mangantes" (20), se revela que Buenos Aires, igual que Barcelona, es una ciudad en venta y que es un "paraíso para los buenos negocios. Y rápidos" (18). Lo que Carvalho descubre es una ciudad que entierra el pasado, igual que Barcelona, para forjar una nueva identidad argentina predicada en los preceptos neoliberales del gobierno de Carlos Menem, que era presidente desde 1989 a 1999. Como le informan a Carvaho, "Ha nacido una nueva Argentina, una nueva argentinidad" (18). Esta identidad nueva moderna se construye literalmente por encima de la historia enterrada de los desaparecidos, especialmente de la clase obrera, que la modernidad ha olvidado: "Se dice que Buenos Aires está construida sobre desaparecidos. La avenida 9 de julio, la más ancha del mundo, tiene bajo su asfalto enterrados a muchos obreros que murieron durante su construcción" (20). El aparente orden de la ciudad, entonces, no revela la barbarie, el desorden y la violencia que ha sido necesario para crearlo.

La retórica del neoliberalismo y los recursos lingüísticos con lemas como "Nueva Argentinidad" también contribuyen a la construcción del orden. Los eufemismos tecnocráticos enmascaran las intenciones y los efectos al co-optar y apropiarse de la conciencia con narrativas que nos atacan continuamente desde cada ángulo con lo que Bourdieu llama do$x a$, cuyo efecto "comes in the end to aquire the quiet force of the takenfor-granted" [termina al final por adquirir la fuerza silenciosa de lo tomado por sentado] (Firing Back, 80). El lenguaje como arma de enmas- 
caramiento, entonces, asimila diferencias políticas bajo la lógica del tardocapitalismo, como la llamaría Jameson, que desintegra ideologías y desarma la resistencia. Así lo señala Alma, la profesora universitaria anfitriona de Carvalho en Buenos Aires: "El menemismo quiso desintegrar a la izquierda integrándola, como el PRI en México" (39). Más adelante se vuelve a enfatizar los efectos homogeneizadores del neoliberalismo y la subversión de la resistencia política cuando un funcionario le indica a Carvalho, "Gracias a Menem, guerrilleros y no guerrilleros todos volvemos a ser peronistas" (80). El hecho que "Nueva Argentinidad" es el nombre de una razón social además del lema del menemismo destaca la integración de la ideología neoliberal en los contextos cotidianos de la ciudad. El instituto de investigación alimentaria y de conducta animal cambió su nombre a "Nueva Argentinidad" pero opera en un edificio "neoclásico de los años cuarenta, con tufillo mussoliniano, y las exaltaciones nacionalistas asaltan continuamente al visitante" (43).

La ciudad como parque temático está visible, afirma Sorkin, en la arquitectura que se desconecta de la historia y adquiere una función puramente semiótica que se informa más por el mercadeo y no responde a las necesidades reales y las tradiciones de la gente que la habita (xiv). Para él, la nueva arquitectura se basa en el engaño y no representa una empresa de diseño urbano sino un disfraz urbano. Y no crea una sensación de lugar sino que ofrece una utopía hiperreal a base del consumo. El pensamiento neoliberal se infiltra e infecta de una forma rizomática que desmantela y desconecta la arquitectura y el entorno construido de su contexto político e histórico, dando lugar a lo que Deleuze y Guattari notan como una desterritorialización que es física, lingüística e ideológica a la vez. No es casualidad que el negocio que habita el edificio descrito arriba sea un laboratorio que trabaje en vacunas para eliminar las enfermedades animales en busca de la purificación de la raza. La "pulcritud científica" (43) del interior del laboratorio refleja los efectos purificadores del neoliberalismo que borra la memoria histórica de los lugares físicos de la ciudad y busca construir una nueva ideología purificada bajo la llamada "nueva Argentinidad." El neoliberalismo asume y asimila la diferencia para proyectar y entender el mundo de una forma única, como se ve en el intercambio entre Carvalho y Güelmes, un ministro del gobierno. Cuando Carvalho le pregunta si el asunto de su primo se trata de un "ajuste de cuentas" relacionado con los tiempos del Proceso, la respuesta del funcionario demuestra cómo los matices lingüísticos se homogenizan dentro de la lógica del capitalismo en la creación de un pensamiento universal: “¿De qué cuentas me hablas? Gracias a Menem, 
todas las cuentas están saldadas" (92). El Estado opera aquí como una máscara que proyecta poder y control, pero realmente sirve de coartada del capitalismo neoliberal que funciona de una forma silenciosa, invisible y transparente. El silencio es precisamente la característica central que señalan Deleuze y Guattari en A Thousand Plateaus: Capitalism and Schizophrenia como el elemento fundamental de un sistema rizomático y descentralizado que carece de agencia, provoca la desterritorialización, y conquista la inconciencia individual por medio de flujos semióticos, materiales y sociales simultáneamente (18-22). La conquista a la cual se refieren no derrama ninguna gota de sangre y la desterritorialización no se manifiesta necesariamente en términos espaciales desde la perspectiva de Deleuze y Guattari sino que se vuelve una simple cuestión de "perceptual semiotics" [semiótica perceptual]. La desterritorialización del capital de los medios de comunicación, los cuales cruzan fronteras y fluyen de forma transnacional sin impedimento ni obstáculo, no provoca la desaparición del Estado como eje jerárquico y estructura de poder en la sociedad sino que lo convierte en un agente más del capitalismo. El individuo, además, asimila los códigos y los vuelve a inscribir, voluntaria o involuntariamente, porque el poder no está centralizado y no está visible sino que se ha vuelto "rizomático" y se ha localizado tanto en los procesos sociales (como ha señalado Bourdieu) como en los políticos, religiosos, artísticos, culturales, etc. La labor no es, en consecuencia, determinar la autenticidad ni encontrar las fronteras entre lo natural y lo artificial, porque las formaciones sociales se vuelven isomórficas según Deleuze y Guattari (no tanto homogéneas, como dice Bourdieu), de tal forma que el individuo se convierte en un autómata (como los animales robóticos de Disney).

En uno de los capítulos de Quinteto, titulado "El hombre oculto," Carvalho encuentra a un hombre que ha asumido el nombre Robinsón Crusoe y va vestido de explorador del siglo XVII además de acompañado por un hombre a quien llama Viernes. Mientras el Robinsón Crusoe de la novela de Julio Verne es un capitalista naufragado en una isla, el Robinsón de Vázquez Montalbán es un ex-capitalista, ingeniero de hidrocarburos, que se encuentra naufragado en un pensamiento izquierdista anticuado y estancado incapaz de renovarse para hacer frente al neoliberalismo. Como hay una "nueva Argentina," la figura de Robinsón le indica a Carvalho que tiene una "nueva vida" pero no se deja llevar por ideas arbitrarias como el optimismo o el pesimismo sino que se declara "esclavo de la lucidez" (185). El proyecto que propone Robinsón es desarrollar una nueva guerra de las Malvinas para la reconquista de Argentina y la "reconquista de la 
razón universal, de los valores de la ética, la solidaridad, la igualdad y la libertad" (207). No obstante, la revolución que busca instigar Robinsón se llevaría a cabo de forma pacífica sin armas para salvar al ecosistema, convocando a los nuevos revolucionarios de la Tierra. La meta de Robinsón es establecer una sociedad utópica al ocupar una o dos de las islas de las Malvinas para predicar un "nuevo orden universal" desde el cual se puede montar una contra-ofensiva ante la globalización. Como ex oligarca que traficaba armas y blanqueaba dinero negro, Robinsón en su vida anterior apoyaba a Videla y la Junta Militar además de la primera guerra en las Malvinas, pero es ese conocimiento íntimo del sistema capitalista y los secretos del Estado que no sólo le libera de definiciones estrictas de la política izquierdista sino que aporta validez a la amenaza revolucionaria que proyecta. Pascuali, el policía argentino en la novela, tomaba en serio su propuesta de recuperar las Malvinas para redimir a la humanidad porque "conocía todas las basuras que ha producido la oligarquía en este país en los últimos treinta años" (251).

No sorprende, entonces, que Robinsón y su asistente Viernes aparezcan muertos, el primero con el cuello cortado y el otro de una sobredosis. En una última escena, Carvalho y Richard Gálvez Jr., el hijo del llamado Robinsón, se reúnen con Ostiz y Maeztu, dos industriales financieros pertenecientes a la clase adinerada de Argentina y responsables por la muerte de Robinsón, para confrontarles por el asesinato. Ostiz y Maeztu declaran su sentido de solidaridad con Robinsón, un hombre patético pero poético, según ellos, y afirman su deseo de buscar alguna manera de no olvidarlo sino guardar su memoria porque, dice Maeztu, "Era de los nuestros, y conviene que se sepa que nosotros pensamos en los demás, que no todo se reduce a crear riqueza" (275). Sacan, entonces, de una inmensa cartera de piel un gran plano arquitectónico que extienden por la mesa y anuncian su plan de honrar la memoria de Robinsón con la construcción de una isla artificial que se llamaría isla "Robinsón Joaquín Gálvez." Isla Robinsón, como la llaman, sería un parque de atracciones que destinaría, explica Ostiz, parte de sus beneficios a la investigación contra nuevas enfermedades. Ostiz explica que ya tienen garantizado el capital básico y que es muy probable que lo puedan relacionar con la Bush, un parque temático en los Estados Unidos. ${ }^{8}$

\footnotetext{
${ }^{8}$ Debería leerse "Busch" si se refiere a Busch Gardens, un parque temático en Tampa Bay, Florida, que se desarrolla inicialmente como un vehículo de comercialización para la compañía de cerveza Anheuser-Busch y ahora está conectado con los parques acuáticos de SeaWorld.
} 
Louis Marin, en Utopics: Spatial Play, denomina este tipo de utopía una utopía degenerada, en la cual hay una función ideológica que causa la alienación del espectador al distorsionar cualquier representación de la vida cotidiana para ocultar los valores que se han obtenido por violencia y explotación - la comodidad, el bienestar, el consumo, el progreso tecnológico, la moralidad-y los proyecta como los efectos lógicos de una sociedad de ley y orden (240). Marin entiende el entorno de Disneyland en términos comunicativos dentro de los cuales el espacio del parque temático se vuelve un escenario y los individuos son actores que juegan el papel de consumidor que lee la narrativa de su itinerario y asimilan la ideología inscrita en él (240). En Travels en Hyperreality, Umberto Eco continua esta línea de pensamiento en la cual se entiende el espacio de Disneyland (y Disneyworld) no como un lugar sino como una forma de comunicar un discurso que falsifica la realidad, la historia, el espacio, al igual que en otros sitios como el OK Corral, Knott's Berry Farm, Astroworld, etc. Para Eco estas "obras maestras de falsificación" (43) borran la línea entre la fantasía y la autenticidad por el realismo de la reconstrucción en la cual el cliente/turista se encuentra como partícipe en la fantasía por su propia autenticidad como consumidor (40). ${ }^{9}$ Además, la falsificación adquiere un nivel ideológico en una ilusión que también simula el deseo por esa ilusión y en la falsificación de nuestra voluntad de comprar se inculca con lo más esencial de la ideología consumidora (42-44). El consumo, o el deseo de consumir, lo falsificado está por todas partes en un lugar como Disneyland (y otros sitios similares), pero donde está más aparente es en el uso de tecnología para crear imitaciones cuya perfección inspira nuestra admiración, y lo que es más importante, nuestra obediencia. Eco nota dos aspectos con relación a la tecnología en Disneyland. El primero es la creencia que la tecnología puede aportar más realidad que la misma naturaleza, pero el segundo es que muchas veces la forma de incorporar la tecnología, especialmente por medio de los llamados "animatrónicos" inventados por Walt Disney, se presenta más como teatro que como ilusión. Por ejemplo, los famosos Piratas del Caribe se presentan como un espectáculo que el turista experimenta y al cual se entrega, y suspende su incredulidad para aceptar la falsificación y con ella su ideología de consumo. Como consecuencia, concluye Eco, este acuerdo entre el espectáculo y el espectador exige la completa pasividad de la persona que visita el parque y le convier-

${ }^{9}$ Esto evoca la obra del autor americano Don Delillo, en particular White Noise (1985) donde se presencia una simulación de una emergencia cuando hay un "desastre" pero nadie sabe si el humo tóxico es de verdad o no. 
te en robot que sacrifica su iniciativa individual y no cuestiona las maneras en que estamos dirigidos por el espacio, física e ideológicamente. Disney, entonces, no es un lugar sino un discurso, como afirma Baudrillard: "The imaginary of Disneyland is neither true nor false, it is a deterrence machine set up in order to rejuvenate the fiction of the real in the opposite camp" (13) [El imaginario de Disneylandia no es ni verdad ni falso, es una máquina de disuasión establecida para rejuvenecer la ficción de lo real en el lado opuesto].

El deseo de Carvalho de des-cubrir la verdad sobre el asesinato de Robinsón y Viernes y, de esta forma revelar el desorden, se topa con esta "máquina disuasoria" cuando intenta volver a la pregunta sobre la responsabilidad del asesinato del padre durante la conversación con Ostiz y Maeztu. Richard Gálvez Jr., hijo del víctima, le dice a Carvalho que deje el tema y el detective, al escuchar "con fluidez" la conversación entre los financieros que pactan la creación del parque temático, se da cuenta que "manejan el mismo código" (277). Más tarde, Carvalho averigua que los tres habían acordado presupuestar veinte millones de dólares para la creación de la isla artificial y cuando el detective expresa su frustración, Gálvez Jr. le responde: "No se sienta defraudado, Carvalho. La verdad no es siempre necesaria" (278).

En Outline of a Theory of Practice, Pierre Bourdieu examina cómo lo que llama doxa, o sea un discurso particular de una clase social o un grupo, caracteriza el habitus donde los "structured structures" [estructuras estructuradas] (72) se rigen por prácticas y representaciones organizadas como estrategias sin ser el producto de una intención estratégica. Crea un círculo hermético en el cual las estructuras económicas y sociales que determinan las condiciones de existencia producen las estructuras del habitus que se vuelven la base de la percepción y el aprecio de toda experiencia subsecuente. Desde la perspectiva de Bourdieu, las condiciones sociales que estructuran el habitus se perciben como objetivas y naturales y como tal se asimilan en la conciencia individual (y colectiva) para producir y reproducir la homogeneidad del habitus. El habitus, afirma Bourdieu, es el producto de un esfuerzo de inculcación y apropiación que informa la conciencia de los individuos que se encuentran en las mismas condiciones materiales. A su vez, esta homogeneidad causa prácticas, creencias, rituales y acciones que no sólo se consideran inteligibles sino que se anticipan hasta tal punto que se vuelven invisibles y se dan por sentado (85). Bourdieu declara luego que los efectos ideológicos más exitosos son aquellos que no necesitan articularse sino que no re- 
quieren más que un silencio cómplice (188), como ha demostrado anteriormente el hijo de Robinsón.

Este silencio reproduce el orden establecido y perpetúa el poder no con violencia sino con invisibilidad en la creación de un simulacro que nos convence de nuestra propia agencia. La búsqueda de autenticidad es otro espejismo, sugiere Vázquez Montalbán, que nos engaña con la idea de que nos movemos cuando en realidad nos mueven. En el viaje no importa el destino sino darse cuenta del acto de viajar y resistir el automatismo que inculca al individuo. La escritura, especialmente la literatura, ofrece el modelo al individuo para adquirir la auto-conciencia y montar la resistencia contra la cultura homogeneizadora. A la vez que la literatura (y la cultura en general) impone modelos de comportamiento, de entendimiento y de conocimiento - como el mismo Robinsón Crusoe - también se subvierte a sí misma para desmitificar el discurso de la cultura, y por extensión cualquier otro discurso. Así, la obra de Vázquez Montalbán, en especial la figura de Carvalho, llama al lector a seguir su modelo de resistencia en la era de la globalización cuando el detective afirma, "Yo soy el último mohicano. [...] Yo estoy al servicio del desorden. Yo soy el desorden" (334).

\section{Bibliografía}

Baudrillard, Jean. Simulacra and Simulation. Translated by Sheila Faria Glaser. Ann Arbor: University of Michigan Press, 1994. Impreso.

Berger, John. Ways of Seeing. Nueva York: Penguin Books, 1972. Impreso.

Bourdieu, Pierre. Firing Back: Against the Tyranny of the Market 2. Translated by Loïc Wacquant. Nueva York y Londres: The New Press, 2003. Impreso.

---. Outline of a Theory of Practice. Cambridge: Cambridge University Press, 1977. Impreso.

Colmeiro, José. Crónica general del desencanto: Vázquez Montalbán Historia y ficción. Barcelona: Anthropos, 2014. Impreso.

Deleuze, Gilles and Guattari Félix. A Thousand Plateaus: Capitalism and Schizophrenia. Translated by Brian Massumi. Minneapolis y Londres: University of Minnesota Press. 1987. Impreso.

Delillo, Don. White Noise. Nueva York: Viking Adult, 1985. Impreso.

Eco, Umberto. Travels in Hyperreality. Traducido por William Weaver. San Diego, Nueva York y Londres: Harcourt Brace \& Company, 1986. Impreso. 
Hammett, Dashiell. The Maltese Falcon. Nueva York: Vintage Books Edition, 1972. Impreso.

Lefebvre, Henri. The Production of Space. Traducido por Donald Nicholson-Smith. Malden, MA y Oxford, UK: Blackwell, Inc., 1991. Impreso.

MacCannell, Dean. The Ethics of Sightseeing. Berkeley: University of California Press, 2011. Impreso

---. The Tourist : A New Theory of the Leisure Class. 9th edition, Nueva York: Schocken, 1976. Impreso.

Marin, Louis. Utopics: Spatial Play. Atlantic Highlands, NJ: Humanities Press, Inc, 1984. Impreso.

Martín-Santos, Luis. Tiempo de silencio. Barcelona: Seix Barral, 1962. Impreso.

Minca, Claudio and Oaks, Tim, editor. Travels in Paradox: Remapping Tourism. Lanham, Boulder, Nueva York, Toronto, Oxford: Rowman \& Littlefield., 2006. Impreso.

Nichols, William J. Transatlantic Mysteries: Crime, Culture, and Capital in the "Noir Novels" of Paco Ignacio Taibo II and Manuel Vázquez Montalbán. Lewisburg, PA: Bucknell University Press, 2011. Impreso.

---. "A quemarropa con Manuel Vázquez Montalbán y Paco Ignacio Taibo II." Arizona Journal of Hispanic Cultural Studies 2.1 (1998) 197-231. Impreso.

Sorkin, Michael editor. Variations on a Theme Park: The New American City and the End of Public Space. Nueva York: Hill and Wang, 1992. Impreso.

Vázquez Montalbán, Manuel. La literatura en la construcción de la ciudad democrática. Barcelona: Crítica (Grijalbo Mondadori), 1998. Impreso.

---. Milenio Carvalho I: Rumbo a Kabul. Barcelona: Planeta, 2004. Impreso.

---. Milenio Carvalho II: En las antípodas. Barcelona: Planeta, 2004. Impreso.

---. Panfleto desde el planeta de los simios. Barcelona: Grijalbo Mondadori, 1995. Impreso.

---. Quinteto de Buenos Aires. Barcelona: Planeta, 1997. Impreso. 